\title{
Desafíos a la educación actual en tiempos de incertidumbre
}

Juan Alexis Parada Silva ${ }^{1}$

\begin{abstract}
Resumen
El presente escrito gravita en torno a tres momentos: en el primero de ellos, se realiza un diagnóstico sobre el individuo y la sociedad contemporánea; en el segundo momento se muestra una caracterización del contexto social teniendo como base la sociedad del riesgo (Beck, 1986), los peligros sociales, políticos, económicos e industriales que amenazan nuestra supervivencia sobre la faz de la tierra, asimismo, señala la incertidumbre en la que estamos inmersos y que gradualmente comprometen nuestras decisiones; y un tercer momento, de la mano del pensador Paulo Freire se señalan algunos desafíos a la educación contemporánea donde la vida parece estar quedando subordinada a los intereses mercantiles y donde los individuos están quedando aislados, y la alternativa que se vislumbra es consumir y consumir.
\end{abstract}

Palabras clave: educación, ética y esperanza, individualismo contemporáneo, sociedad de consumo, sociedad del riesgo. 


\title{
Current challenges to education in times of uncertainty
}

\begin{abstract}
This writing revolves around three times: in the first, a diagnosis on individuals and contemporary society is made; the second time a characterization of the social context on the basis of the risk society (Beck, 1986), social risks, political, economic and industrial threaten our survival on the face of the earth, also shown, indicates uncertainty which are immersed and gradually compromise our decisions; and a third time, hand thinker Paulo Freire some challenges contemporary education where life seems to be being subordinated to commercial interests and where individuals are being isolated, and the alternative that is emerging is to consume and consume listed.
\end{abstract}

Keywords: Education, individualism contemporary consumer society, risk society, ethics and hope.

Recibido: 06-03-2014

Aceptado: 18-06-2014

\section{La soledad de los individuos}

Ya lo señalaba el pensador alemán Inmanuel Kant en su escrito: «Idea de una historia universal con propósito cosmopolita» (1784) acerca de la insociable sociabilidad del hombre, un antagonismo que implica muchos retos a la sociedad y a la educación. Por un lado, el hombre busca su desarrollo individual, su autonomía, su libertad; por otro, tiene una propensión innata de buscar el desarrollo individual siendo parte de una sociedad. En la educación esto se ve marcado sobremanera, ya que entra en conflicto esta doble naturaleza, el egocentrismo versus la convivencia. Tanto Bauman, como Lipovetsky denuncian una marcada tendencia al individualismo, (lo insociable), dejando atrás los intereses colectivos (lo sociable), de esta forma se afecta la coexistencia y priman los intereses particulares por encima de los generales. Lo estamos palpando a diario con la acumulación de unos pocos y la pobreza de muchos. Se calcula que en las manos de 400 individuos se encuentra cerca del 80\% de la riqueza mundial.

La cultura de masas ha exaltado la vida del ocio, la felicidad y el bienestar individuales, ha promovido una ética lúdica y consumista de la vida. Los temas centrales de la cultura de masas han contribuido poderosamente a la afirmación 
de una nueva forma de la individualidad moderna, centrada en su realización privada y su bienestar (Lipovetsky, 1983: 252).

Lipovetsky señala que se ha creado una cultura de masas que exalta lo festivo, la juerga, el espectáculo, el consumo, el show, que desestima el papel relevante de la persona en la sociedad y que le da primacía al goce meramente individual, donde se da cabida al derroche de satisfacción de los sentidos.

Asimismo, el sociólogo francés considera que gracias a la cultura de masas, creada por el imperio de la publicidad, ha eclosionado una nueva concepción antropológica denominada el Homo Consumans, que se preocupa sólo en consumir, en cultivar un estilo de vida hedonista centrado en su bienestar particular: La aspiración a realizarse, a gozar de inmediato de la existencia, no es un equivalente simple del adiestramiento del homo consumans: lejos de embrutecer a los hombres mediante la distracción programada, la cultura hedonista estimula a cada cual a convertirse en dueño y poseedor de su propia vida, a auto determinarse en sus relaciones con los demás y a vivir más para sí mismo (Lipovetsky, 1983: 201).

Efectivamente, se necesita de los demás para sobrevivir, sin embargo, en esta sociedad de consumo, la relación con los demás se efectúa buscando el provecho particular, la pregunta es ¿Qué puedo ganar en esta relación? Esto se aplica en el plano afectivo, familiar y laboral. Donde la interacción está cargada de un gran contenido de intereses, sobre todo de índole económico. De igual forma, esta sociedad de consumo, que promueve el Homo Consumans, se ha valido de la publicidad y de los medios de comunicación para volver un espectáculo escenarios propios de la vida de las personas, tales como la política: "La política espectáculo enmascara los problemas de fondo, sustituye los programas por el encanto de la personalidad y entorpece la capacidad de razonamiento y juicio en provecho de las reacciones emocionales y de los sentimientos irracionales de atracción o antipatía. Con la media política, los ciudadanos se han infantilizado, ya no se comprometen en la vida pública y son alineados y manipulados a través de artilugios e imágenes; la democracia se ha desnaturalizado y pervertido. La política show no se contenta con anestesiar al ciudadano mediante la diversión, transforma incluso los mismos contenidos de la vida politica" (Lipovetsky, 1983: 226).

La sociedad de consumo ha promovido no sólo una política que adormece al individuo sino que además a través de la moda viene enrutando a los seres humanos por la vía del embrutecimiento, la falta de compromiso, la desmotivación, la indiferencia, la insolidaridad, acabando gradualmente con la razón y encumbrando estereotipos o modelos a seguir, pero que rayan en la superficialidad, el compromiso está mandado a recoger, sólo se da cabida al confort, al consumo y a la diversión. La ética es reemplazada por la estética, poco importa el ¿Cómo actúas?, se le da mayor prelación al ¿Cómo te ves? 
Ni siquiera el ¿Cómo te sientes? tiene validez, lo importante es la fachada, lo exterior, lo que muestras, lo que ostentas, lo que portas, lo que llevas, lo que compras, lo que consumes. Una cultura como la nuestra que tolera el lavado de activos y ve con buenos ojos el dinero proveniente de actividades ilícitas, es una cultura que ya está corroída, que urge re-fundarla, reconceptualizarla, nutrirla de valores y de principios innegociables, se necesita volver a la ética como un estilo de vida y no como un accesorio para mostrar.

La idolatría a los objetos y al espectáculo, sumado a una moral hedonista y centrada en lo material, están socavando los pilares de la sociedad -si se puede hablar todavía de ella-. En una sociedad de consumo poco importa la cualificación profesional sino la mano de obra barata e ignorante; se trata es de entretener y no de educar, y los que le apuestan a la formación profesional llegan cundidos de una especie de enfermedad, donde todo aburre, todo genera indiferencia, lo anterior le plantea varios retos a la educación, pues, se espera que los docentes sean lúdicos y hasta manejen técnicas recreativas para hacer llamativas las diferentes ciencias. Sí es preciso aclarar que algunos docentes, todavía enseñan al estilo prehistórico y se creen los únicos poseedores del conocimiento, no incorporan a sus prácticas educativas las TIC y no se actualizan bibliográficamente, no obstante, existen otros docentes que diariamente se están cualificando y se les dificulta enfrentar esta cultura del ocio, del menor esfuerzo, de la diversión que gradualmente se está generalizando en los jóvenes estudiantes.

Hacen falta la fiesta, el rock, los conciertos y las exposiciones bonachonas plagadas de eslóganes de tono humorístico-publicitario. Ahora los actores sociales abrazan el universo de la imagen, del espectáculo, de los media, del estrellato, de la moda, de la publicidad... el compromiso moral es al mismo tiempo emocional, engancha, es divertido, festivo, deportivo, musical... el compromiso en cuerpo y alma ha sido sustituido por una participación pasajera, a la carta, a la que uno consagra el tiempo y el dinero que quiere y por la que se moviliza cuando quiere, como quiere y conforme a sus deseos primordiales de autonomía individual (Lipovetsky, 1983: 320).

Y como estamos ocupados consumiendo imágenes, eslóganes, cremas, realities, fútbol y reinas, se inserta en nosotros paulatinamente la cultura de la evasión, donde se olvida la miseria, la exclusión, la monotonía, la desigualdad y gradualmente también nos hacemos corresponsables con la pobreza, ya que nos falta compromiso, y si lo hay es intermitente, por ciclos, acordes al estado de ánimo, sin exigencia ni sacrificios, efectivamente, sí tenemos preocupaciones humanitarias, pero cada vez más nos falta filantropía, generosidad, colaboramos por colaborar sin saber por qué lo hacemos o para qué lo hacemos, o tal vez lo hacemos para quedar bien.

La sociedad moderna, una sociedad que incita al consumo, que conlleva a la depresión que promueve confusión existencial, donde hay más «desarrollo» 
del individuo pero una mayor degradación de la sociedad. El sociólogo francés se cuestiona acerca de ¿Cómo restaurar una sociedad, donde el individualismo moderno, está tan entronizado?

Fin de la tradición, inestabilidad de las normas de socialización y superindividualización de los seres, la moda plena, como último nivel del estado social democrático, no hace sino promover con mayor insistencia la cuestión del principio de cohesión de las sociedades contemporáneas. ¿Cómo una sociedad, constituida por unidades libres e independientes, sin ningún nexo sustancial de socialibilidad, puede reconocerse como una? ¿Cómo una sociedad desligada de los vínculos comunitarios tradicionales, constituida por individuos autónomos, fluctuantes y cada vez más encerrados en sí mismos, puede escapar al proceso de desintegración y mantenerse unida? (Lipovetsky, 1983: 311).

Lo anterior se constituye en una tarea enorme tanto para la política, la cultura, la educación, como para la misma sociedad, ¿Cómo reconstruir el tejido social, con bases sólidas y confiables?, ¿Cómo recuperar la confianza en la política cuando está plagada de corrupción y de intereses particulares?, ¿Cómo recuperar la imagen de las instituciones educativas que se han dejado llevar por un modelo cuantitativo, donde lo importante es mostrar resultados dejando a un lado los escrúpulos?, ¿De qué forma configurar un modelo que promueva el cultivo de valores como la convivencia, la tolerancia, el compartir, la empatía, cuando las actuaciones de los padres de la patria y de los dirigentes del país, no están encaminadas a ello?, ¿Cómo fomentar una contracultura que en vez de promover el éxito, la competencia individual y los estereotipos se preocupe por fomentar el diálogo, la reflexión, el debate y el aprender a vivir juntos?

Estos interrogantes no son de fácil contestación, requieren un estudio profundo y a conciencia, que tenga en cuenta el contexto y que ofrezca soluciones de fondo, no tanto de forma. Consideramos que redefiniendo la educación y apostándole a esta se puede avanzar en elementos valiosos al menos, los relacionados con la sociabilidad.

La sociedad de consumo a través de sus estrategias de mercado como la publicidad nos ha vendido la receta para muchas de nuestras actividades cotidianas: qué comer, dónde hacerlo, cómo mantenerse joven, cómo ser padres hoy, que comprar, que leer, cómo vestirnos, qué estudiar ${ }^{2}$, dónde hacerlo, a dónde viajar, por quién votar en las elecciones, qué programas ver; la sociedad de consumo nos tiene en sus manos, porque a través de los mass media prácticamente determinan nuestra vida, nos tienen condicionados. Ahora bien, quienes intenten salir de ese círculo vicioso, son marginados, están out, fuera de onda, son orates o al menos esos suelen ser los calificativos utilizados en los mismos medios o en el argot popular.

2. No importa que te guste o no, se trata de que estudies algo que tenga salida, es decir, que genere buenos dividendos, por eso es que es muy frecuente ver profesionales frustrados, que intentan quitarse la frustración desatando su ira con los subalternos. El saber por el saber, está mandado a recoger, se estudia con un fin, generalmente económico. Otro problema muy frecuente es el de las especializaciones donde el profesional se olvida del gran campo disciplinar y se concentra en una parte del mismo, entablando una relación parcial con el saber, el saber se fractura, se parcela, por ejemplo, el médico especialista, se le olvida el conjunto, la medicina en general y así sucede en casi todos los campos, (verbigracia, el derecho) 
Asimismo, se siembra un nuevo paradigma de ser humano, el homo consumans (ya reseñado) quien está dispuesto a renunciar hasta a los principios con tal de obtener dinero, para seguir incursionando en el mágico mundo del mercado, de la compra impulsiva, muchas veces sin sentido, entonces se trata de entablar negocios, que generen buenas utilidades, es así como: El negocio es tanto un medio para conseguir una situación económica desahogada como un modo de realizarse a sí mismo, de superarse, de tener un objetivo estimulante en la vida. La estructura narcisista del Ego domina; por un lado, se trata de tener dinero para gozar en privado de los bienes y servicios de la vida moderna y por otro, de hacer algo por sí y para sí mismo, conocer la excitación, la aventura o el riesgo (Lipovetsky, 1983: 287).

\section{El consumo como una estrategia de escape}

Se nos ha impuesto una nueva profesión: la de ser compradores, ya sea compulsivos, moderados, o recatados, no importa, lo que realmente importa es comprar. La acción de comprar se erige como el verbo de moda, como la actividad donde se exorciza al ser humano de la gran incertidumbre que genera el existir en la actualidad. Sólo comprando se calma el desasosiego que produce el existir. El comprar genera un alivio temporal, asimismo crea una identidad momentánea, la del poseer. Se es importante, por lo que tienes, no por lo que eres o al menos esa es la identidad que se propugna en la sociedad de consumo. Ahora el peligro es para los que no tienen, ya que son excluidos. Ellos deben hacer hasta lo imposible para conseguir el dinero que les permita el lujo de tener, no importa si les toca vender su dignidad, su reputación, ni mucho menos si les toca renunciar a sus principios, casi todo se negocia por dinero. El dinero se ha convertido en un fin y no en un medio como realmente lo es. La gente se ha transformado en un producto que se vende y se compra al mejor postor, todo con el objetivo de tener dinero, para a su vez comprar artilugios, que calman la incertidumbre transitoriamente. Para la gente no hay elección, toca comprar, comprar, no importa si la casa es de tablas, o de barro, con tal de tener el equipo de sonido de última generación, no importa endeudarse con el objetivo de tener el celular más novedoso.

Tener recursos significa tener libertad de elegir, pero también -y eso es lo más importante- significa tener libertad de soportar las consecuencias de las malas elecciones y, por lo tanto, libertad del atributo menos deseable de la vida de elección. Por ejemplo, el «sexo plástico», el «amor confluente» y «las relaciones puras», los aspectos consumistas de las relaciones humanas de pareja, fueron descritos por Anthony Giddens como vehículos de emancipación y garantía de una nueva felicidad... una nueva escala, sin precedentes, de autonomía individual y libertad de elección (Bauman, 2003: 22). 
Ahora bien, si al ir de compras no «elegiste» bien, tienes la posibilidad de desechar lo comprado y volver por otro producto que satisfaga tu sed de comprador. Eso sí las consecuencias para tu bolsillo y para el planeta no se hacen esperar. Recordemos que ahora estamos inmersos también en una cultura de lo desechable, aplicable inclusive a las mismas relaciones afectivas.

Tener recursos nos puede proteger momentáneamente de la obsolescencia de los productos comprados, pero desafortunadamente, no nos protege del mismo deseo de comprar, el cual nos produce una efímera sensación de satisfacción.

¿Qué nos queda para salvarnos nosotros y para salvar al planeta, si ya no hay utopía ni distopía sino sólo un individualismo acentuado?, ¿Será que nos toca asumir como agentes libres nuestra propia reconstrucción? Existe incertidumbre, también social.

\title{
La sociedad actual: una sociedad de problemas, riesgos y amenazas
}

\begin{abstract}
"Riesgo no es sinónimo de catástrofe. Riesgo significa la anticipación de la catástrofe. Los riesgos señalan la posibilidad futura de ciertos acontecimientos y procesos, hacen presente una situación mundial que aún no existe. En el momento en que los riesgos se convierten en realidad (Explota una central nuclear o se produce un atentado terrorista) se convierten en catástrofes... Los riesgos son siempre acontecimientos futuros que nos amenazan y, puesto que esta amenaza permanente determina nuestras expectativas, invade nuestras mentes y guía nuestros actos, resulta una fuerza política transformadora" (Beck, 2007: 27).
\end{abstract}

Frente a un individualismo remarcado y una concepción antropológica soportada en el ideal del Homo Consumans, el panorama continúa un poco desalentador. En este apartado, el diagnóstico reflexivo que nos ofrece el sociólogo alemán Ulrich Beck no cambia el panorama, sigue cundiendo una especie de escepticismo respecto al futuro; no obstante, el ejercicio de Beck nos ofrece herramientas conceptuales para entender nuestra sociedad, una sociedad que está ad-portas de un colapso, debido en gran parte a la irresponsabilidad de los seres humanos frente a la naturaleza y al manejo de la ciencia bajo el hito del progreso, al respecto el sociólogo alemán asevera: "El mundo no es como es, sino que su ser y su futuro presuponen decisiones, decisiones que ponderan ventajas e inconvenientes, trenzan progreso y ruina y, como todo lo humano, albergan el error, el no saber, la hybris, las promesas de control y al final incluso el germen de una posible autodestrucción" (Beck, 2007: 21). 
Se puede afirmar que Ulrich Beck se erige como un «profeta» de nuestro tiempo, pues logra presentar un panóptico general del contexto social, donde hay un acentuado individualismo y un desmoronamiento del tejido social. Asimismo, bajo la categoría de riesgo, logra englobar grandes peligros para el ser humano, que de no tomarse cartas en el asunto de forma oportuna, pueden ocasionar gradualmente la extinción de la especie.

El pensador alemán distingue, en su análisis crítico de la sociedad, diferentes características que hacen de nuestro entorno un espacio en riesgo inminente, riesgo que puede desembocar en una tragedia. En las siguientes líneas deseo mencionar los rasgos más sobresalientes con los cuales Beck describe a nuestra sociedad:

La sociedad del riesgo está caracterizada por el reino de la incertidumbre, por la pérdida de horizonte (al menos común), por la entronización del individuo y por un consumismo voraz y tenebroso. Una consecuencia de ello se hace sensible en la vida cotidiana de la sociedad del riesgo mundial: el repunte de la individualidad. Ante la incertidumbre del mundo global, el individuo tiene que tomar sus propias decisiones. Esta nueva forma de individualización se deriva del fracaso de los expertos al gestionar el riesgo. Ni la ciencia ni la política dominante ni los medios de comunicación ni la economía ni el derecho, ni siquiera el ejército, pueden definir racionalmente o controlar los riesgos. El individuo se ve forzado a desconfiar de las promesas de la racionalidad de dichas instituciones. Las consecuencias es que las personas se ven remitidas nuevamente a sí mismas: desarraigo sin arraigo (ésta es la fórmula trágica e irónica a la vez de esta dimensión de la individualización en la sociedad del riesgo global (Beck, 2007: 87).

En la sociedad del riesgo no existen asideros, ni bases sólidas, todo resulta líquido, lo único seguro es que no hay nada seguro, las cosas son pasajeras, las leyes son momentáneas y cualquier cosa puede pasar. Lo terrible de lo anterior es que como no se sabe a ciencia cierta que va a pasar, se suele caer en un escepticismo total (no se cree ni se espera nada) o se puede caer en un desespero por el mañana, todo angustia, hasta el silencio es cuestionado, porque puede ser sinónimo de tragedia. No estamos preparados para lo que viene, estamos desprevenidos y sin herramientas para actuar en caso de emergencia ${ }^{3}$. Al respecto Beck asevera: A diferencia de todas las épocas anteriores (incluida la sociedad industrial), la sociedad del riesgo se caracteriza esencialmente por una carencia: la imposibilidad de prever externamente las situaciones de peligro (Beck, 1986: 237).

Al deificar la economía, el ser humano queda supeditado a los intereses de quienes la ostentan. El hombre se convierte así en un medio, en un objeto, 
se cosifica. Entonces gracias a la instrumentalización del ser humano, se le degrada, se le enferma y se le asesina. Surgen los conflictos donde se enfrentan dos discursos, de por sí antagónicos, uno se encuentra liderado por aquellos que empuñan la bandera del progreso y la ganancia, el otro discurso está representado por los «insurgentes» liderado por aquellos que se preguntan ¿Hasta cuándo seguirá siendo vituperada la naturaleza (incluida la humana)?, ¿Hasta cuándo el ser humano seguirá actuando de forma irresponsable frente al planeta?, ¿Hasta cuándo aguantará la naturaleza los ataques insolentes del hombre? El cambio climático, por ejemplo, es producto del éxito de la industrialización, que desprecia sistemáticamente sus efectos sobre la naturaleza y el ser humano (Beck, 2007: 25).

Ahora bien, se nos quiere hacer creer, que todos somos culpables de la destrucción del planeta, y gracias a los medios de comunicación se nos busca concientizar sobre la importancia del reciclaje y del uso racional del agua (eso está bien, no estoy en contra de ello), mi voz de protesta se alza en contra de las cortinas de humo que se levantan para arropar la verdadera responsabilidad de los contaminantes de este mundo, y en gran parte causantes de la hecatombe ecológica. Recordemos que son los países industrializados los que contaminan enormemente nuestro terruño y son ellos mismos los reacios a emprender acciones puntuales y eficaces en contra del calentamiento global (cabe destacar las últimas cumbres: Kyoto, Johannesburgo y Río, donde las grandes potencias vienen postergando acciones que minimicen el daño ambiental) ${ }^{4}$. A la par con este tópico ya hemos adelantado otro rasgo de la sociedad del riesgo, el que compromete nuestra supervivencia. Los riesgos que proceden de las grandes tecnologías y la industrialización son resultado de decisiones conscientes (tomadas por un lado, por organizaciones privadas y/o estatales para obtener ventajas económicas y aprovechar las correspondientes oportunidades y, por otro, sobre la base de un cálculo que considera los peligros como la inevitable cara oculta del progreso). Los peligros vinculados a la industrialización se convierten en política no en virtud de su magnitud sino en virtud de una peculiaridad social: no es el destino el que nos lo envía sino nosotros quienes lo creamos: son productos de manos y cabezas humanas, fruto de la unión de saber técnico y cálculo económico (Beck, 2007: 49).

Se hace perentorio que re-surja la crítica desde la misma ciencia para consigo misma. Urge una ciencia que prevea los peligros y errores que pueden surgir de la implementación de los avances investigativos. Es necesario poner en tela de juicio la clase de futuro incierto que se está fraguando gracias al desarrollo técnico-científico. La puesta en marcha de los descubrimientos en genética, nanotecnología y robótica dejan entrever la improvisación y la incipiente preparación de los individuos para con las consecuencias, en muchos casos nefastas, que se desprenden de los mismos. Se deben trazar límites a la investigación científica para que no sigan atentando contra la supervivencia 
humana y estos límites deben eclosionar desde la propia sociedad, concretándose en instancias políticas que impulsen reglas claras, creíbles y efectivas. Los estamentos políticos y decisorios de las naciones deben recuperar su incidencia social y promover acciones en aras a preservar nuestro planeta.

También, apremia que los emporios económicos acepten su responsabilidad en la catástrofe ecológica y promuevan avances tecnológicos donde se vinculen energías limpias y a favor de la especie humana, se requiere re-habitar el planeta.

Asimismo es un anhelo que la ciencia sea cada vez más humana, que se pueda comprender que los que la realizan son seres humanos falibles, que se equivocan, que tienen aciertos y desaciertos, que se apasionan, que tienen inclinaciones apetitivas e intereses de por medio. De esta forma se puede comprender que la ciencia y su consigna del progreso científico al ser hecha por humanos, está expuesta al error, a la duda y a consecuencias adversas en detrimento de la especie humana. El progreso científico debe estar abierto a la posibilidad de su rectificación y reconocerse como algo inacabado y en constante cambio, aceptando críticas y aportes en todo su proceso.

\section{Desafíos a la educación contemporánea en tiempos de incertidumbre}

Ahora la pregunta clave es: ¿Qué hacer para contrarrestar esa lógica destructiva que se ancla sólo en intereses particulares? ¿Acaso desde la educación se pueden promover acciones puntuales que disminuyan los peligros inminentes de exterminio de la especie en los que estamos inmersos?

Consideramos que la educación sí les puede aportar mucho a las personas en aras a cambiar este panorama desalentador. Es clave que la educación como proceso formativo gravite en torno a valores humanos que impulsen una nueva ética de la investigación donde se desmantele el discurso de individuos exitosos en sociedades fracasadas.

Son varios los desafíos que debe asumir la educación en tiempos de incertidumbre

1. Encauzar, pensando en el futuro de las generaciones venideras, el discurso de la lógica del mercado, al que sólo le importan los beneficios particulares por encima del bienestar colectivo.

2. Ser el portavoz a la par con la comunidad científica de una ética planetaria (evocando una propuesta de Leonardo Boff, que apunta sobre este tópico) que ondee las banderas de la responsabilidad, donde se evalúen los riesgos de los productos científicos antes que se implementen y se susciten nuevas reglamentaciones que limiten el uso indiscriminado de los recursos naturales, sin importar el lugar. 
3. Urge promover desde los claustros una formación integral de las personas, donde no sólo se aprendan los núcleos básicos de la formación profesional, sino que además se retomen discusiones en torno ¿Al sentido de lo humano?, ¿Los límites de la ciencia?, ¿El papel de la política?, ¿El aprender a vivir juntos?

4. Es indispensable que se concrete un cambio de mentalidad donde: $n a z c a$ otra manera de comprender la naturaleza y su relación con la sociedad, de comprendernos a nosotros mismos y a los otros, así como de comprender la racionalidad social, la libertad, la democracia y la legitimación (incluso de comprender al individuo) (Beck, 2007: 36). Las cavilaciones educativas pueden coadyuvar a pensar en la conciliación entre individuo y naturaleza. Donde las actuaciones de los individuos en conjunto apunten a reconciliarse con el medio ambiente.

5. La educación deberá enfrentar la concepción predominante que concibe al saber como una mercancía, como una transacción, como un producto que se puede adquirir, que se puede vender, que es susceptible de ser medido. Hay entonces, una mercantilización del saber. En la sociedad «posmoderna» el individuo entra en la lógica del saber como mercancía, pues si quiere sobresalir, debe hacer parte de las nuevas sociedades del conocimiento, donde el saber es un poder, y se manifiesta fuertemente, en las decisiones que se desprenden del mismo, pues, gracias al avance del saber científico, se toman decisiones que afectan a toda la humanidad.

6. El hombre posmoderno, está obligado a estudiar algo que no le apetece, sólo con el objetivo de calar en el engranaje de la demanda del mercado mundial. Se les impone estudiar «algo que sirva», algo rentable, esto incrementa la cantidad de profesionales frustrados, ahogados en su profesión. Se trata de estudiar algo que se pueda vender, que sea eficaz, que lo convierta a uno en competente, que lo prepare para enfrentarse al mundo laboral que se caracteriza por ser cada vez más inhumano e injusto.

7. La educación contemporánea debe propiciar el desarrollo máximo de las posibilidades del individuo y de igual forma, promover la convivencia, la tolerancia, la alteridad y la responsabilidad conjunta. Asimismo, la educación debe enfrentar el individualismo remarcado en la sociedad de consumo y confrontar el ideal antropológico del Homo Consumans, que sólo busca satisfacer sus propios caprichos sin pensar en los demás, con el Homo Responsum, con el sujeto consciente que responde por las decisiones tomadas en su devenir cotidiano y que no se escuda en la crisis económica, en la globalización, en el mercado para justificar sus actuaciones. En el Homo Responsum debe anclarse la educación contemporánea, para minimizar los efectos devastadores del individualismo contemporáneo. El Homo Responsum es un sujeto que configura sus comportamientos acorde a 
la permanencia de la vida humana en la faz de la tierra y que hace uso de la razón para realizar las mejores elecciones a favor de todos los seres vivos. Este ideal antropológico del Homo Responsum nos obliga a comprender mejor al otro, a ser empáticos.

8. Urge un cambio de conciencia individual y social, es perentorio concebir la educación como un todo, no sólo como un ente aislado que sirve para la adquisición de conocimientos, en detrimento de otras formas de aprendizaje, sino ver en la educación una herramienta eficaz para reorientar el rumbo caótico de la sociedad actual. Se espera al igual un compromiso por parte de las naciones para buscar y elaborar políticas educativas incluyentes e innovadoras que inspiren y convoquen la participación de todos los implicados.

9. La educación debe ser problematizadora, suscitar procesos de reflexión sobre el entorno, que permita realizar una lectura del mundo y de las condiciones inequitativas del mismo.

10. La educación debe abonar el terreno propicio para que las personas desarrollen el máximo de sus potencialidades.

11. Es imperioso que la educación identifique los gustos, los deseos, los pensamientos y la curiosidad de los educandos para edificar un currículo abierto y dispuesto a insertar dentro de su dinámica espacios dialógicos, reflexivos y de crecimiento mutuo.

12. La escuela debe propender por no ser un agente de reproducción social, económica y cultural, dado que en estos aspectos se promueven la dominación, la exclusión, la competencia y una ideología capitalista que consume al hombre y hace que crezca la brecha entre los que ostentan y los que no. Hay que superar la visión tradicionalista de la educación, donde las escuelas se erigían como centros escolarizados donde sólo importaba la instrucción, donde la acriticidad era la constante y no se ofrecía esperanza alguna y el panorama resultaba desalentador.

13. Los educadores debemos trabajar en la transformación de las condiciones presentes de dominación y concretar una vida futura donde la reflexión y la acción crítica se constituyan en acicates de un proyecto social que no sólo supere la opresión sino que aporte en la consecución de un modelo de vida humanista y humanizante.

14. Las escuelas se deben erigir como verdaderos centros culturales y políticos con diferentes ideologías donde se permee el cambio, el debate y la reflexión. 
15. La escuela debe ser un escenario de controversia y de discusión permanente. El estudiar debe ser una forma de reinventar, recrear y reescribir la realidad.

16. Freire reclama en la educación un acto epistemológico, donde lo que se enseñe esté ligado necesariamente al conocer, al conocer la realidad y sus vericuetos, sus engaños y desengaños, a saber: La práctica educativa es naturalmente gnoseológica y no es posible conocer nada a no ser que nada se sustantive y se vuelva objeto para ser conocido, es decir se vuelva contenido. La discusión fundamental es política. Tiene que ver con qué contenidos enseñar, a quién, a favor de qué, de quién, contra qué, contra quién, cómo enseñar. Tiene que ver con quién decide sobre que contenidos enseñar, qué participación tienen los estudiantes, los padres, los maestros, los movimientos populares en la discusión en torno a los contenidos programáticos (Freire, 1997:53).

17. En tiempos de incertidumbre y de caos la educación debe empuñar las banderas de la esperanza y de un porvenir mejor. La educación debe relacionar la esperanza con la práctica para cristalizarse en historia concreta y de esa forma servir como acicate para promover transformaciones de raíz en la sociedad. La educación colmada de esperanza, debe a través de la práctica realizar análisis serios y puntuales de la realidad donde se dejen entrever situaciones donde las personas puedan crear y recrear sus entornos. Donde puedan luchar por sus sueños, donde puedan concretar sus anhelos, donde denuncian las iniquidades y anuncien un reencuentro con la libertad.

18. La educación debe fomentar el dialogo, suscitar la creatividad personal y colectiva, promover la lectura crítica del contexto, propiciando sujetos críticos-reflexivos que asuman su historia, luchen por los valores y la permanencia de la vida por encima de la cultura necrófila que se promueve desde el silencio. La educación debe ser humanista, esperanzadora, profética y liberadora.

19. La educación debe ser una apuesta constante por la vida, por la libertad, confiando en el ser humano, que piensa, ríe, sueña, ama, que tiene necesidades, que está supeditado por la economía. Si nada queda de estas páginas, esperamos que por lo menos algo permanezca: nuestra confianza en el pueblo. Nuestra fe en los hombres y en la creación de un mundo en el que sea menos dificil amar (Freire, 1970:71).

20. Los seres humanos como sujetos históricos deben propender por cambiar el mundo, por transformar las condiciones infrahumanas en las que se encuentran, pero este es un proceso, y un proceso que exige hacer y rehacer: Haciéndose y rehaciéndose en el proceso de hacer la historia, 
como sujetos y objetos, mujeres y hombres, convirtiéndose en seres de la inserción en el mundo y no de la pura adaptación al mundo, terminaron por tener en el sueño también un motor de la historia. No hay cambio sin sueño, como no hay sueño sin esperanza (Freire, 1993:116)

\section{Referencias bibliográficas}

Bauman, Z. 2003. La modernidad líquida. Madrid: Espasa.

Beck, U. 2007. La sociedad del riesgo mundial. Barcelona: Paidós.

Beck, U. 1986. La sociedad del riesgo: Hacia una nueva modernidad. Barcelona: Paidós.

Delors, J. 1998. La educación encierra un tesoro. Barcelona: Santillana.

Freire, P. 1997. La educación en la ciudad. México: Siglo Veintiuno Editores.

Freire, P. 1970. Pedagogia del Oprimido. Recuperado el 30 de Mayo de 2012, de Pedagogia del Oprimido: www.ensayistas.org/critica/liberacion/varios/freire.pdf

Freire, P. 1993. Politica y educación. Caracas: Laboratorio Educativo.

Kant, I. 1784. Idea de una historia universal en sentido cosmopolita. Publicado por primera vez en: "Berlinische Monatsschrift", November 1784, S. 385-411, bajo el título: Idee zu einer allgemeinen Geschichte in weltbürgerlicher En castellano: http://www. redfilosofica.de/kant2002.html (acceso en 2008)

Lipovetsky, G. 1983. La era del vacio. Madrid: Anagrama.

Lyotard, J. F. 1987. La condición Posmoderna. Madrid: Cátedra. 